\title{
O ENSINO DA PSICANÁLISE NA GRADUAÇÃO EM PSICOLOGIA: PERCEPÇÃO DE PROFESSORES SOBRE A TRANSMISSÃO
}

\author{
Sílvia Nogueira Cordeiro ${ }^{1}$ \\ Maria Elizabeth Barreto Tavares dos Reis ${ }^{2}$ \\ Maíra Bonafe Sei ${ }^{3}$ \\ Sandra Aparecida Serra Zanetti ${ }^{4}$
}

\begin{abstract}
RESUMO: Entende-se que o ensino e a transmissão da psicanálise implicam o diálogo entre dois aspectos: conhecimento acadêmico - objetivo e sistemático - e conhecimento produzido pela psicanálise - dinâmico e subjetivo. Objetivou-se, assim, discutir a percepção de docentes sobre o ensino e a transmissão da psicanálise na graduação em psicologia de uma universidade pública. Realizou-se um estudo qualitativo por meio de entrevistas semiestruturadas com docentes da área de psicanálise. Observou-se que, para os docentes, a universidade é um lócus de ensino e pesquisa em psicanálise, destacando-se a especificidade de seu modelo de transmissão, que considera o sujeito e seu desejo como inseparáveis do ato de ensinar e de pesquisar. Acredita-se, a despeito dos limites inerentes à transmissão da psicanálise no cenário universitário, que o ensino desta deve ser fomentado, despertando o interesse dos futuros psicólogos por este campo do saber.
\end{abstract}

Palavras-chave: Universidade. Psicanálise. Psicologia.

\footnotetext{
${ }^{1}$ Psicóloga, Doutora em Tocoginecologia na área de Ciências Biomédicas pela Universidade Estadual de Campinas. Professora Associada do Departamento de Psicologia e Psicanálise da Universidade Estadual de Londrina. E-mail: silvianc@uel.br

${ }^{2}$ Psicóloga, Doutora em Psicologia Clínica Universidade de São Paulo. Docente do Departamento de Psicologia e Psicanálise da Universidade Estadual de Londrina. Email: bethtavares@uel.br

${ }^{3}$ Psicóloga, Doutora em Psicologia Clínica pelo Instituto de Psicologia da Universidade de São Paulo, Professora Associada do Departamento de Psicologia e Psicanálise da Universidade Estadual de Londrina. E-mail mairabonafe@gmail.com.

${ }^{4}$ Psicóloga, Mestre, Doutora e Pós-doutora em Psicologia Clínica pela Universidade de São Paulo. Email: sandra.zanetti@gmail.com
} 


\title{
PROFESSORS' PERCEPTION OF PSYCHOANALYSIS TEACHING IN AN UNDERGRADUATE PROGRAM IN PSYCHOLOGY
}

\begin{abstract}
The teaching and the transmission of psychoanalysis imply a dialogue between two aspects: academic knowledge - objective and systematic - and knowledge produced by psychoanalysis - dynamic and subjective. The objective of this research was to discuss the perception of professors of the education and the transmission of psychoanalysis in a psychology degree program at a public university. We conducted a qualitative study using semi-structured interviews with professors in psychoanalysis. According to the professors, a university is an educational and research locus in psychoanalysis, highlighting the specificity of its transmission model, which considers the subject and his desire as inseparable from the act of teaching and research. Despite the inherent limits in the transmission of psychoanalysis in a university setting, they believe the teaching of this subject should be promoted, awakening the interest of future psychologists in this field of knowledge.
\end{abstract}

Keywords: University. Psychoanalysis. Psychology.

\section{PERCEPCIÓN DE LOS PROFESORES DE LA ENSEÑANZA DE PSICOANÁLISIS EN UN PROGRAMA DE PREGRADO EN PSICOLOGÍA}

RESUMEN: Se entiende que la enseñanza y transmisión del psicoanálisis implica un diálogo entre dos aspectos: el conocimiento académico - objetivo y sistemático - y el conocimiento producido por el psicoanálisis - dinámico y subjetivo. Así, el objetivo fue discutir la percepción de los docentes sobre la enseñanza y transmisión del psicoanálisis en psicología de pregrado en una universidad pública. Se realizó un estudio cualitativo a través de entrevistas semiestructuradas con profesores del campo del psicoanálisis. Se observó que, para los docentes, la universidad es un locus de docencia e investigación en psicoanálisis, destacando la especificidad de su modelo de transmisión, que considera al sujeto y su deseo como inseparables del acto de enseñar e investigar. Se cree, a pesar de los límites inherentes a la transmisión del psicoanálisis en el escenario universitario, que se debe fomentar su docencia, despertando el interés de los futuros psicólogos en este campo del conocimiento.

Palabras clave: Universidad. Psicoanálisis. Psicología. 


\section{Introdução}

A transmissão da psicanálise na universidade é uma questão que remonta aos seus primórdios, tendo ocupado lugar nos escritos freudianos já no início de sua obra. Em 1918, Freud (1919[1918]/1976) publicou o ensaio "Sobre o ensino da Psicanálise nas Universidades". Trata-se de um pequeno artigo em que discorre sobre a possibilidade de intersecção entre dois tipos de produção de conhecimento, a saber, o conhecimento acadêmico, objetivo e sistemático, e o conhecimento produzido pela psicanálise, dinâmico e subjetivo (FREUD, 1919[1918]/1976; ROSA, 2001).

Para Freud, não seria possível articular a formação psicanalítica num curso universitário. Coutinho et al. (2013) comentam que a possibilidade de recompensa individual ou de satisfação do desejo pessoal de se tornar um analista não seria condizente com a formação curricular universitária. Por outro lado, sustentar o ensino da psicanálise pela via da explicitação conceitual e em suas articulações com a cultura seria possível e importante para uma formação geral universitária. Neste sentido, a universidade, e particularmente a escola médica, só teria a ganhar com a inclusão do ensino da psicanálise em seu currículo, que não se restringiria aos "distúrbios psíquicos" (FREUD, 1919/2010, p. 380), mas se estenderia a campos como a arte, filosofia e religião.

Freud (1919/1920) imaginou um efeito fertilizante do pensamento psicanalítico sobre vários campos do conhecimento, capaz de criar entre eles uma ligação mais estreita. A indicação seria, portanto, oferecer a psicanálise como curso geral e introdutório tanto para as ciências quanto para as artes e as humanidades "no sentido de uma universitas literarum" (FREUD, 1919/2010, p. 381).

Portanto, a integração desses dois tipos de saber - da universidade e da psicanálise - distintos entre si, convoca a tecer reflexões acerca dos vieses decorrentes dessa aproximação. Poderia a psicanálise ser ensinada no âmbito universitário? Se possível, como se daria essa transmissão?

O discurso de Freud (1919/2010) propõe que, apesar de a inclusão da psicanálise em seu currículo ser de grande utilidade para o saber acadêmico, a recíproca não seria verdadeira, ou seja, a psicanálise nada teria a ganhar com o conhecimento advindo da universidade. Essa reticência em relação à universidade pode fazer eco com a sua história pessoal pois, como se sabe, Freud foi rejeitado em 
sua postulação de se tornar professor universitário e o ensino de suas ideias foi praticamente banido da Faculdade de Medicina.

No entanto, o ensino da psicanálise na universidade é polêmico desde a época de Freud. Há os psicanalistas que defendem a perspectiva de que não se pode transmitir a psicanálise na universidade, pois não se torna psicanalista valendo-se do ensino que se recebe no curso de graduação. Outros defendem que é na universidade e não nas instituições psicanalíticas que será preservado o ensino da psicanálise (ROSA, 2001).

Há dois eixos que problematizam o encontro da psicanálise e a universidade. Por um lado, a formação do psicanalista pressupõe três pilares fundamentais: o estudo teórico, a supervisão e a análise pessoal. Do outro lado, o ensino da psicanálise na universidade se fundamenta no ensino, na pesquisa e na prestação de serviço (SOUZA, 2000).

Freud (1923[1922]/1976) apresenta o termo psicanálise de três formas: como um procedimento para a investigação de processos mentais, que são quase inacessíveis por qualquer outro método, como um método (baseado nessa investigação) para o tratamento de afecções psíquicas e, por fim, um conjunto de informações psicológicas obtidas que, gradualmente, se acumulam numa nova disciplina científica. Por meio da psicanálise, Freud inaugura um modo de compreender o homem, que implica descentrá-lo da certeza cartesiana, trazendo consequências para a transmissão e o ensino dessa nova ciência (FREUD, 1923[1922]/1976).

A questão que envolve a transmissão da psicanálise consiste em um saber a ser comunicado, um saber que é implantado pelo método psicanalítico. Contudo, este saber ultrapassa, segundo a mesma definição, a dimensão prático-clínica, que corresponde à díade metodológica investigação-tratamento. Desdobra-se na construção de um corpo teórico articulado com as descobertas clínicas, o objeto que faz a intersecção entre psicanálise e universidade.

Em se tratando da parte teórica da psicanálise, o objetivo da transmissão acadêmica seria a divulgação do conhecimento psicanalítico, em seu rigor conceitual, um espaço para a discussão dos elementos constituintes dessa teoria (FREUD, 1919[1918]/1976). Mezan (1993), explorando o pensamento de Laplanche, indica que o ensino da psicanálise na universidade não se propõe como um atalho à formação 
analítica, imprescindível à prática clínica em psicanálise, mas como um meio de contato com a teoria psicanalítica.

O conhecimento psicanalítico, tendo inaugurado um novo campo do saber, passando a considerar a importância e a influência dos processos mentais inconscientes, inaugura também um saber não objetivável, diferente de todo o conhecimento que vinha sendo postulado, tanto por seu objeto de estudo quanto pelo método utilizado para a análise desse objeto. É dessa especificidade do campo psicanalítico que surge a dificuldade de integração com o tipo de conhecimento que sustenta a academia.

Ao considerar a transmissão da psicanálise e a formação do psicanalista, Ferraz (2014, p. 94) aborda as diferenças entre o estudo teórico da psicanálise - tendo a própria teoria como objeto - e o estudo da "metapsicologia como ferramenta que ocupará um lugar na escuta psicanalítica". A teoria não irá preceder a escuta, mas, sim, abordar a especificidade da escuta psicanalítica. O estudo da teoria psicanalítica como objeto ocorre na academia, lembrando que a produção intelectual sobre a psicanálise amplia os horizontes e desvenda as raízes dos conceitos tomados por empréstimo de outras ciências. Entretanto, para que ocorra a formação psicanalítica, é necessário conhecer o inconsciente não apenas teoricamente, mas "experimentá-lo na situação transferencial" (FERRAZ, 2014, p. 94).

Muitos candidatos a analistas chegam aos institutos destinados à formação psicanalítica levando vínculos transferenciais anteriores e conhecimentos teóricos bem estabelecidos, sendo alguns formados como doutores ou livre docentes nas universidades (MION, 2014). No entanto, durante a formação psicanalítica, há necessidade de se fazer o resgate do si mesmo, resgatar algo que já estava lá desde o princípio, o que não é sabido. Assim, o "processo de formação analítica não consiste simplesmente na aquisição de conhecimentos que informam o analista. Trata-se também da desconstrução de um saber" (MION, 2014, p. 108).

Neste sentido, conceitos como inconsciente, pulsão, transferência e repetição, fundamentais para a psicanálise, requerem um trabalho cuidadoso na transmissão de seu ensino, uma vez que aquilo que os caracteriza é o fato de serem construídos a partir da prática clínica, que não se resume a uma objetivação positivista. Além disso, a inserção da psicanálise nos cursos de graduação em psicologia pode descaracterizar 
a psicanálise se ela for tomada a partir dos conceitos da psicologia, ou seja, da teoria da consciência, ou ser incluída nas psicoterapias de reforço do eu (SANTOS, 2002).

Apesar dos impasses surgidos na inserção da psicanálise na universidade, não se pode desconsiderar o fato de que a disciplina de psicanálise se encontra, atualmente, incorporada à grade curricular dos cursos de psicologia. Tem-se uma divulgação e expansão não só na perspectiva clínica, mas também como método interpretativo que permite a leitura de diferentes fenômenos em que o homem está inserido (ROMERA; ALVARENGA, 2010).

Para Kupfer (2010), a diferença fundamental entre os campos da psicanálise e da educação está na noção de sujeito. "Os inúmeros sujeitos presentes nas concepções e teorias pedagógicas da atualidade não coincidem com o sujeito da psicanálise" (p. 266). Contudo, apesar da diferença, a autora é defensora da ideia de que a noção de sujeito do inconsciente, própria da psicanálise, pode ser instalada na base de algumas práticas, capazes, inclusive, de renovar ações educativas que predominam ainda hoje no campo da educação (KUPFER, 2010). O sujeito que Freud (1919[1918]/1976) apresenta é um sujeito não mais pensado como livre e agente da própria vida, mas como um "sujeito-efeito" (KUPFER, 2010, p. 268). O sujeito do inconsciente é um termo que foi formulado por Lacan como um "lugar, uma função, que, ao se revelar à revelia do Eu, denuncia um desejo desconhecido por esse Eu que suporta essa subjetividade" e resulta da "incidência de discursos sociais e históricos sobre a carne do ser." (KUPFER, 2010, p. 270).

Assim, Kupfer (2010) conclui que todo professor que optar por trabalhar com essa noção de sujeito terá que abandonar a ideia de um sujeito livre e autônomo e se ocupar da perspectiva de um sujeito descentrado, sujeitado, determinado pelas práticas socioculturais e pelas forças libidinais. Essa mudança fará o professor perceber que o estudante não é uma tela em branco na qual se tenta inserir, pintar conhecimentos, mas pensado como uma escultura, em que se precisa extrair da pedra elementos para que o sujeito que jazia no ser possa emergir.

Diante deste cenário, destacamos as condições atuais do ensino da psicanálise no curso de graduação em psicologia em uma instituição pública de ensino superior (IES). A psicanálise está diretamente inserida no eixo teórico das disciplinas Fundamentos de Psicanálise I e II, Psicanálise e Processos Sociais e Teoria e Técnicas 
Psicoterápicas. De forma indireta, faz-se presente em algumas unidades dos programas de disciplinas como Psicologia do Desenvolvimento e Psicopatologia. Por fim, consta na grade curricular por meio dos estágios supervisionados do último ano do curso, tanto no atendimento clínico como no atendimento à comunidade (escola e instituições).

Esta forma de trabalho atualmente implica uma divisão no ensino e na transmissão da psicanálise, pois, nos primeiros anos, concentra-se o ensino teórico, enquanto o atendimento clínico e a supervisão acontecem somente no último ano do curso. Entende-se esta como uma questão problemática para a psicanálise, uma vez que deixa acontecer uma fissura entre aprendizagem, a transmissão e a intervenção. De maneira a se lidar com a intensa divisão entre teoria e prática existente no curso em questão, implementou-se, em 2014, um novo currículo cuja proposta é aproximar o ensino teórico e prático. Entretanto, observa-se que as estratégias de ensino nem sempre contemplam essa almejada aproximação.

Trabalhando na direção de se refletir sobre a natureza do ensino da psicanálise no contexto universitário, a presente pesquisa almejou mapear e discutir a percepção de docentes acerca da forma de ensino e transmissão da psicanálise na graduação em psicologia desta universidade pública.

\section{Metodologia}

Trata-se de um estudo qualitativo (TURATO, 2005), empreendido por meio de entrevistas com os docentes que ministram disciplinas sobre os fundamentos teóricos e práticos da psicanálise no curso de graduação em psicologia. O projeto foi aprovado pelo Comitê de Ética em Pesquisa com Seres Humanos da instituição em questão, número do parecer 724.3332, com participação voluntária e assinatura do Termo de Consentimento Livre e Esclarecido.

\section{Participantes}

Foram entrevistados individualmente todos os docentes que ministram disciplinas com conteúdos sobre fundamentos da psicanálise, com exceção de dois professores que eram coordenadores desta pesquisa, totalizando oito docentes. Os professores que participaram da pesquisa foram identificados com a letra $p$ (professor) 
e o número de ordem em que ocorreram as entrevistas, como forma de garantir o sigilo e o anonimato. Trata-se, assim, de uma amostra proposital (TURATO, 2003), com escolha deliberada de respondentes, composta a partir de critério de exaustão, haja vista que todos os docentes, exceto os coordenadores da pesquisa, participaram do estudo.

\section{Procedimentos}

Foram formuladas quatro questões norteadoras para investigar os seguintes aspectos: como consideram o ensino e transmissão da psicanálise na universidade, estratégias didáticas utilizadas, receptividade dos alunos quanto às estratégias utilizadas e sua percepção quanto à realização dos objetivos propostos nas disciplinas.

Foram conduzidas duas entrevistas de aculturação (TURATO, 2003), das quais participaram dois professores do referido curso que ministravam outras disciplinas e que não seriam participantes da pesquisa. Buscou-se, assim, testar o instrumento delineado, verificando a compreensão e assimilação do sentido das perguntas propostas. Não foram evidenciadas dificuldades nas questões nem necessidade de reformulá-las.

As entrevistas foram gravadas, transcritas e analisadas a partir de uma análise de conteúdo temática (BARDIN, 2011), a partir da qual foram delineadas categorias tendo em vista os objetivos do estudo. Compreende-se categorias como "enunciados que abarcam um número variável de temas, segundo seu grau de intimidade ou proximidade, e que possam através de sua análise, exprimirem significados e elaborações importantes que atendam aos objetivos de estudo e criem novos conhecimentos" (CAMPOS, 2004, p. 614). Para tanto, foram trilhadas as seguintes etapas: 1) pré-análise, 2) exploração do material, 3) tratamento dos resultados (BARDIN, 2011). Para discussão dos dados, fez-se uso dos seguintes documentos: grades curriculares, com dados das disciplinas e suas ementas, e projeto político pedagógico do curso de psicologia envolvido na pesquisa.

\section{Resultados}

Após a análise minuciosa das entrevistas transcritas, buscando encontrar tópicos relevantes sobre a maneira como os docentes consideravam a possibilidade de 
ensinar e transmitir os conteúdos teórico-práticos da psicanálise no curso de graduação em psicologia, foi possível verificar que algumas ideias se repetiram nas falas dos docentes, as quais foram categorizadas como: 1. Necessidade de investimento por parte dos alunos; 2 . A organização da grade curricular não favorecer o ensino da psicanálise; 3 . Necessidade de estabelecimento de vínculo entre professor e aluno.

1. Necessidade de investimento por parte do aluno

Segundo a percepção dos entrevistados, o curso de graduação em psicologia possibilita ao aluno apenas uma aproximação mínima aos conteúdos da psicanálise. Há necessidade de investimento pessoal além do contato acadêmico, para que o aluno possa, de fato, se apropriar da psicanálise.

Os professores expressaram suas opiniões por meio das seguintes falas:

O professor tem uma função estabelecida de um lugar de quem sabe. E, com a psicanálise, a característica do campo solicitaria outro lugar. $O$ aluno precisava ser mais protagonista. Este lugar solicita uma decisão. Na universidade a psicanálise é vista apenas como uma orientação teórica. (P1, \&)

Eu vejo como uma possibilidade do aluno se inserir parcialmente no universo que ele vai ter que continuar depois [...] Aqui chamamos mais a atenção para a necessidade de que o aluno não busque a formação somente numa universidade, apesar de vir buscando aqui primeiramente. A psicanálise tem esse limite. Dá pra fazer muita coisa nesse limite. Mas aí ele [o aluno] vai ter que dar conta do particular. (P5, \&)

As falas dos professores nesta categoria colocam em pauta algo muito importante para a psicanálise: a questão do desejo, essa experiência particular que traça o curso das ações do indivíduo, que baliza suas escolhas e indica seus interesses. Ao dizer que é preciso, por parte do aluno, que haja um investimento, uma aposta na direção do "saber psicanálise", o que se indica é a necessidade de que a psicanálise seja tomada pelo desejo para que se produza algum movimento individual na direção desse saber.

Estudo realizado por Bertoldi, Folberg e Manfroi (2013) com alunos do curso de medicina participantes de um projeto sobre relação médico-paciente mostrou que a exigência desses alunos para adquirir competências e saberes era entendida como se 
fosse vinda de fora, de outro lugar, lugar simbólico onde a consciência não tem acesso. A partir da demanda deste outro, associa-se, na psicanálise, o sujeito da linguagem, dividido em sua verdade e saber. Ainda que este estudo não se refira diretamente ao ensino de psicanálise, ele reforça a concepção de que, para apreender, é preciso algo mais para que seja possível sustentar os esforços e a dedicação pertinentes à academia.

Se tomarmos como ponto de partida a asserção de que "a pulsão sublimada transforma-se em pulsão do saber" (KUPFER, 2001, p. 86), poderíamos supor que esta dificuldade apontada pelos professores seja algo que ultrapassa os limites da sala de aula e que esteja intimamente relacionada ao funcionamento do desejo do aluno; portanto, está relacionada às suas questões pessoais. Todavia, conforme Laplanche (1992), seria uma atitude de descrença no dinamismo inconsciente e em sua capacidade de responsividade da realidade privar os não analistas dos fundamentos da psicanálise por não estarem num processo de análise formal. Isto quer dizer que, embora não se possa, de fato, esperar que o estudante aprenda na universidade a prática da psicanálise como seria em um instituto, é possível que ele aprenda algo da psicanálise (SANTOS FILHO, 2013). Entretanto, essa possibilidade de ensinar conteúdos acerca da psicanálise na universidade, esbarra, segundo os relatos dos professores, na dificuldade que a teoria - complexa, múltipla e muito ramificada - apresenta, conforme a categoria a seguir.

2. A organização da grade curricular não favorece o ensino da psicanálise

A estrutura curricular da graduação em psicologia não permite que a psicanálise tenha o espaço necessário e minimamente suficiente na formação em função da demanda por proporcionar ao aluno uma visão ampla dos diversos campos do saber nos quais a teoria e a prática da psicologia estão inseridas.

A obrigatoriedade das disciplinas impossibilita o aprofundamento nas questões da psicanálise. Este aprofundamento é mais possivel em projetos onde a avaliação não é requisito para aprovação. (P2, ९)

Eu acho que é uma tentativa. Eu acho que é uma possibilidade de ampliar a visão sobre a psique humana. Mas é aquela questão, não sei se é efetiva para formar um psicanalista. Enfim, uma parte do curso é dedicada a isso. (P4, §) 
Observa-se que a maneira como os cursos de graduação em psicologia estão organizados implica atender uma gama de conteúdos, tanto gerais da psicologia quanto específicos aos diversos campos de atuação e abordagem teóricometodológica, sendo a psicanálise apenas certo montante nesse grande todo. Assim, a carga horária das disciplinas relativas à psicanálise constitui apenas uma pequena parcela do conhecimento a ser transmitido e apreendido, considerando a profundidade e abrangência dos estudos necessárias ao mínimo que o psicanalista ou psicólogo clínico necessita conhecer para, de fato, se apropriar da teoria psicanalítica.

Segundo Santos (2002), quando se pensa na questão do ensino da psicanálise nos cursos de psicologia, assim como da própria inserção de seus conteúdos na estrutura curricular, não se pode deixar de observar uma tendência de objetivação dos conceitos de psicanálise. Como sinalizado na introdução, o autor afirma que a “inserção da psicanálise no campo da psicologia contribui para diluir a teoria e a prática da psicanálise no terreno difuso das teorias da consciência e das psicoterapias de reforço do eu" (SANTOS, 2002, p. 1).

Por outro lado, Aguiar (2000) argumenta que a psicologia clínica tem um papel fundamental na divulgação e expansão da psicanálise na França e a psicanálise, por sua vez, contribui com os seus fundamentos dando identidade à psicologia clínica. Esse processo é consequência do ensino da psicanálise no âmbito da universidade, sendo os psicanalistas os responsáveis pelas disciplinas de psicanálise.

No Brasil, algo semelhante acontece, uma vez que a psicanálise faz sua entrada na universidade pela aproximação do psicanalista à academia. Atualmente, encontramos um número significativo de psicólogos clínicos e praticantes da psicanálise ministrando disciplinas de psicanálise nas instituições (MIELKE, 2013). Contudo, conforme apontado por Mezan (2002), o primeiro contato dos psicanalistas com a universidade é uma surpresa, pois se trata de um ambiente ao qual não estão habituados, distante da clínica e mais próximo das questões teóricas e da pesquisa sobre temas de psicanálise. Essas observações aproximam-se do que foi exposto nas falas dos docentes entrevistados, que pareceram deixar transparecer um desconforto em adequar a práxis da psicanálise à formação acadêmica, o que acaba exigindo do docente uma constante reflexão acerca do seu fazer e da forma como adapta os conteúdos da disciplina a modos específicos do seu ensino. 
Nesta mesma direção, Macedo e Dockhorn (2015) afirmam que, diante da necessidade de atender aos ideais de inclusão na comunidade científica, não se pode perder de vista a particularidade e consistência que fundamentam a especificidade da psicanálise. Há, portanto, a necessidade de reinventar a psicanálise, conforme indica Lacan (1978), sendo essa uma tarefa dos psicanalistas que procuram transmitir, como um teórico, a prática da psicanálise e não simplesmente aplicar o conhecimento adquirido na sua formação (AIRES, 2103).

Figueiredo (2008) observa que, no curso de graduação, só é possível um saber sobre a psicanálise. Não há como aprofundar o conteúdo, mas é possível recolher os efeitos de um primeiro contato com a psicanálise para aqueles alunos. Do lado do professor, é necessário não apenas um saber sobre o conteúdo como também, um saber que possibilite a mediação do conhecimento.

Sobre este aspecto sabe-se que os conteúdos teórico-práticos necessários para a compreensão dos fundamentos da psicanálise são extensos e demandam dedicação e muito tempo de leituras, debates, atendimentos clínicos supervisionados e autorreflexão. Entretanto, frequentemente, o ensino da psicanálise na universidade acontece por meio da exposição de pequenas partes que não formam um todo.

Os professores assim expressaram suas considerações a respeito:

Freud já dizia que educar é a arte do impossivel. Mas é claro que eu entendo que existe uma formação básica. Não é formação de psicanalistas. Esse ensino fica multifacetado, uma cocha de retalhos. (P3, \&)

Ainda vejo um conteúdo de psicanálise mínimo, de manchete, distorcido, onde só se fala sobre alguns recortes da psicanálise. $O$ aspecto teórico é insuficiente. É uma psicanálise diminuta. $(P 7$, O)

Os docentes entrevistados relembram as ideias de Freud (1919/2010) sobre a dificuldade de ensinar a psicanálise. Ao mesmo tempo em que abordam a possibilidade de o aluno aprender os fundamentos básicos da teoria psicanalítica, ressaltam que a transmissão ocorre de forma fragmentada e insuficiente. Percebe-se que os docentes consideram insuficiente o montante de conteúdo psicanalítico ofertado; além disso, criticam a forma como os conteúdos precisam ser distribuídos nas diversas disciplinas. 
Assim, demonstram o desejo de que a psicanálise pudesse ocupar um espaço maior dentro da grade curricular prevista para a graduação em psicologia.

Foi possível observar que os docentes procuram dar curso ao conteúdo programático criando meios para superação das dificuldades encontradas. Alguns docentes ressaltaram a escolha pelas aulas expositivas, mas, ao mesmo tempo, ficam em dúvida quanto ao conteúdo possivelmente absorvido em função da percepção de uma baixa participação dos alunos em sala de aula, seja pela heterogeneidade, pela falta de prática de leitura ou mesmo de interesse dos alunos pelas disciplinas de psicanálise, ainda que saibam da importância desse conteúdo para sua formação. Os docentes também consideraram quase impossível avaliar de forma efetiva, como e quanto o aprendizado efetivo ocorreu.

Neste sentido, Monteiro (2002) aponta que, assim como a universidade não forma os profissionais em medicina, levando-os a buscar aperfeiçoamentos a posteriori para suas formações, também não almeja formar psicanalistas. No que diz respeito à psicanálise, o objetivo do ensino universitário é que o estudante possa apreender algo sobre a psicanálise e a partir da psicanálise.

3. Necessidade de estabelecimento de vínculo entre professor e aluno

O aluno precisa estabelecer um vínculo especial na relação professor-alunoconteúdo que possibilite, mesmo que minimamente, a aproximação e o diálogo acerca da psicanálise. Assim seria possível o desenvolvimento de uma relação transferencial positiva entre o aluno e as respectivas díades docente-disciplina e docente-aluno, favorecendo o desejo de aprender sobre a psicanálise e posteriormente sobre o caminho a seguir na busca pela sua própria formação como psicanalista.

A disciplina é obrigatória [...] mas até por ser obrigatório poucos alunos se envolvem. (P2, §)

Cada um vai sendo levado por uma onda relacionada ao próprio desejo e escolha. (P3, §)

Aqueles alunos que se interessam pela psicanálise acompanham. (P4, §)

O professor é tomado como significante. Há uma escolha do aluno e da transferência dele. (P8, (7)

As percepções dos professores sobre a forma como os alunos se relacionam com o processo de aprendizagem deixa transparecer a importância de reconhecer o sujeito do inconsciente nas práticas educativas. Para a psicanálise, é de fundamental 
importância entender o que norteia o processo educativo, considerar o sujeito do inconsciente na educação, sujeito que não segue o modelo científico e os ideais da ciência. Conforme mencionado por Kupfer (2010), o aluno deve ser considerado como sujeito-efeito.

Dentro do contexto psicanalítico, o processo educativo pode implicar um destaque à figura do professor como aquele que, inevitavelmente, é convocado a ocupar um lugar que transcende a prática pedagógica tradicional, estabelecendo uma relação transferencial, relação esta que propicia que o aprendizado seja esculturalmente construído (KUPFER, 2010).

Neste sentido, na educação, é contemplado o sujeito do conhecimento cognitivo e este conhecimento é passível de mensuração. Como visto, o sujeito com o qual se ocupa a psicanálise é o sujeito do inconsciente, com manifestação única, singular, não mensurável e que, por isso, não pode fazer parte do concretamente observável.

Lacan (1964/1998) menciona que "O ensino da psicanálise só pode se transmitir de um sujeito a outro e isso pela via de uma transferência de trabalho" (p. 236). Portanto, esta seria uma via para o ensino da psicanálise também na universidade e o professor deveria sustentar a via de transmissão que se fundamenta na causalidade psíquica.

Neste contexto, o professor pode representar, para o aluno, uma função de suporte dos investimentos afetivos, representando então esse lugar de 'saber', de idealização, de poder. Esta posição em que o professor se encontra não é um lugar fácil de sustentar, pois nele estão depositadas projeções alheias a sua pessoa. O professor ignora esse lugar que lhe é outorgado pelo aluno, pois é o desejo inconsciente desse aluno que está determinando o lugar a ele conferido. Como consequência, é atribuído ao professor um poder que caracteriza a sua autoridade, ou seja, a autoridade do professor não é imposta ao aluno, mas outorgada ao professor pelo próprio aluno (NUNES, 2004).

A autoridade não depende do desejo do professor e sequer é algo consciente. Estrutura-se a partir do encontro entre duas pessoas que estão em posição de desigualdade na qual, principalmente em relação ao conhecimento, um dos elementos está em posição de suposto saber para o outro. Nesse sentido, a autoridade não é 
imposta e sim decorrente do processo transferencial que se estabelece na relação entre aluno e professor.

Outro aspecto levantado por Kupfer (1999) é que "o professor pode organizar seu saber, mas não tem controle sobre os efeitos que produz sobre seus alunos" ( $p$. 97), pois não conhece as muitas repercussões inconscientes de seus ensinamentos e de sua própria figura em relação ao aluno. Compreende-se que o olhar psicanalítico sobre o processo de ensino-aprendizagem proporciona uma reflexão sobre a posição de poder potencialmente ocupada pelo professor e sobre a tentação de abusar desta posição (KUPFER, 2001).

Seguindo este raciocínio, Nunes (2004) defende que é pertinente o professor sustentar sua posição de representante do conhecimento, mas, ao mesmo tempo, reconhecer-se e apresentar-se ao aluno como sujeito faltante. Na medida em que, na relação educativa, o professor é o sujeito detentor daquilo que falta ao aluno, se o professor se coloca na posição daquele que "tudo sabe", fica para o aluno somente a possibilidade de submeter-se à posição de objeto frente ao professor, ficando mais difícil se constituir como sujeito desejante do saber (NUNES, 2004).

Neste sentido, podemos observar que a ênfase da psicanálise se concentra principalmente nas relações afetivas entre professores e alunos, colocando em destaque o desejo de saber do aluno e o desejo de formar do professor como elementos decisivos para a concretização da aprendizagem. O foco de análise não se volta, portanto, aos conteúdos, mas ao campo afetivo que se estabelece entre o professor e seu aluno e que estabelece as condições para o aprender (KUPFER, 1999).

\section{Considerações finais}

Esta pesquisa organizou-se como um estudo qualitativo que procurou investigar e discutir a percepção de aspectos referentes ao ensino e transmissão da psicanálise dentro de um curso de graduação de psicologia na visão dos docentes ligados à área. Indica-se não haver uma pretensão de concluir o tema, mas de trazer reflexões sobre como o professor percebe o ensino da psicanálise na universidade em questão.

A partir desta investigação, observou-se que os docentes entrevistados expressaram nas suas falas o desejo de que a psicanálise dispusesse de maior tempo na carga horária curricular, o que poderia levar o aluno a desenvolver um vínculo de 
aprendizagem mais intenso com ela. Segundo a percepção de um dos entrevistados, é preciso mobilizar recursos para que se possa estabelecer uma ligação e fazer do ensino um trabalho enriquecedor, ainda que faltem as condições ideais.

É pertinente criar uma atitude acolhedora e, ao mesmo tempo, rigorosa com as tarefas - consequência das transferências presentes no processo de aprendizagem e na relação professor-aluno. Neste sentido, sugerimos que pesquisas futuras possam investigar fenômenos em que o professor assume uma função de suporte dos investimentos afetivos, um lugar de "saber", de idealização, que, imagina-se, interferem na forma como o conteúdo será assimilado pelo aluno, na dinâmica de sua aula, no próprio investimento do professor em sua prática e na relação deste com os alunos.

Observou-se um consenso entre os docentes entrevistados de que a formação do psicanalista vai além da academia e que ela, sim, implica algo mais, considerando a necessidade da vivência não só da prática clínica, como da supervisão de casos e da análise pessoal, bem como do aprofundamento dos conhecimentos teóricos iniciados na graduação da universitária. A graduação em psicologia apenas possibilita os primeiros contatos com a teoria psicanalítica e o estabelecimento de vínculos transferenciais que podem levar à busca pelo aprofundamento teórico-prático nos cursos de pós-graduação lato e stricto sensu e também pela formação psicanalítica propriamente dita. Entende-se, contudo, que, a despeito desses limites, a psicanálise se mostra como um campo do conhecimento que deve ser apresentado ao futuro psicólogo, enriquecendo sua visão sobre o campo da psicologia clínica (AGUIAR, 2000), estimulando possíveis aprofundamentos futuros do profissional junto a esta área do saber.

\section{Referências}

AGUIAR, F. Psicanálise e universidade: das relações entre a psicologia clínica e a psicanálise na França. Estudos de Psicologia (Natal), v. 5, n. 1, p. 215-241, jun. 2000. Disponível em: http://www.scielo.br/scielo.php?script=sci_arttext\&pid=S1413294X2000000100010\&Ing=en\&nrm=iso. Acesso em 12 set. 2017.

AIRES, S. Imagem do analista na universidade. Trivium: estudos interdisciplinares, v. V, n. 1, p. 30-38, 2013. Disponível em: https://www.uva.br/trivium/edicoes/edicao-i- 
ano-v/artigos-tematicos/imagens-do-analista-na-universidade.pdf. Acesso em 12 set. 2017.

BARDIN, L. Análise de conteúdo. São Paulo: Edições 70, 2011.

BERTOLDI, S. G.; FOLBERG, M. N.; MANFROI, W. C. Psicanálise na educação médica: subjetividades integradas à prática. Revista Brasileira de Educação Médica, v. 37, n. 2, p. 202-209, 2103. Disponível em:

http://www.scielo.br/scielo.php?script=sci_arttext\&pid=S0100-

$55022013000200007 \&$ Ing=en\&nrm=iso. Acesso em 08 jan. 2020.

CAMPOS, C. J. G. Método de análise de conteúdo: ferramenta para a análise de dados qualitativos no campo da saúde. Revista Brasileira de Enfermagem, v. 57, n. 5, p. 611-614, 2004. Disponível em:

http://www.scielo.br/scielo.php?script=sci_arttext\&pid=S0034-

71672004000500019\&Ing=en\&nrm=iso. Acesso em 08 jan. 2020.

COUTINHO, D. M. B. et al. Ensino da psicanálise na universidade brasileira: retorno à proposta freudiana. Arquivos Brasileiros de Psicologia, v. 65, n. 1, p. 103-120, jun. 2013. Disponível em:

http://pepsic.bvsalud.org/scielo.php?script=sci_arttext\&pid=S1809$52672013000100008 \&$ Ing=pt\&nrm=iso. Acesso em 12 set. 2017.

FERRAZ, F. C. Transmissão e formação: apontamentos sobre o tripé analítico. Jornal de Psicanálise, v. 47, n. 86, p. 87-102, jun. 2014. Disponível em: http://pepsic.bvsalud.org/scielo.php?script=sci_arttext\&pid=S0103$58352014000100010 \&$ Ing=pt\&nrm=iso. Acesso em: 12 set. 2017.

FIGUEIREDO, A. C. Psicanálise e universidade: reflexões sobre uma conjunção ainda possível. Fractal: Revista de Psicologia, v. 20, n. 1, p. 237-252, jun. 2008. Disponível em: http://www.scielo.br/scielo.php?script=sci_arttext\&pid=S1984$02922008000100022 \&$ Ing=en\&nrm=iso. Acesso em: 12 set. 2017.

FREUD, S. Deve-se ensinar a psicanálise nas universidades? In: FREUD, S. História de uma neurose infantil: ("O homem dos lobos"): além do princípio do prazer e outros textos (1917-1920). São Paulo: Companhia das Letras, 2010. p. 377-381. (Texto originalmente publicado em 1919).

FREUD, S. Sobre o ensino da psicanálise nas universidades. In: FREUD, S. Edição brasileira das obras psicológicas completas de Sigmund Freud. Rio de Janeiro: Imago, 1976. p. 380-385. (Texto originalmente publicado em 1918/1919). 
FREUD, S. Dois verbetes de enciclopédia. In: FREUD, S. Edição brasileira das obras psicológicas completas de Sigmund Freud. Rio de Janeiro: Imago, 1976. p. 296-298. (Texto originalmente publicado em 1922/1923).

KUPFER, M. C. M. Freud e a educação, dez anos depois. Revista da Associação Psicanalítica de Porto Alegre, v. 1, n.16, p. 14-26, 1999.

KUPFER, M. C. M. Freud e a educação. O mestre do impossível. Pensamento e ação no Magistério. São Paulo: Scipione, 2001.

KUPFER, M. C. M. O sujeito na psicanálise e na educação: bases para a educação terapêutica. Educação e Realidade, v. 35, n. 1, p. 265-282, 2010. Disponível em: https://seer.ufrgs.br/educacaoerealidade/article/view/9371/5412. Acesso em: 08 jan. 2020.

LACAN, J. A psicanálise e seu ensino. In: LACAN, J. Escritos. Rio de Janeiro: Jorge Zahar, 1998. p. 438-460. (Texto originalmente publicado em 1964)

LAPLANCHE, J. O inconsciente e o id. São Paulo, SP: Martins Fontes, 1992.

MACEDO, M. M. K; DOCKHORN, C. N. B. F. Psicanálise, pesquisa e universidade: labor da especificidade e do rigor. Perspectivas en Psicología, v. 12, n. 2, p. 82-90, 2015. Disponível em: https://dialnet.unirioja.es/descarga/articulo/5294247.pdf. Acesso em: 12 set. 2017.

MEZAN, R. Que significa pesquisa em psicanálise? In: SILVA, M. E. L. (org.). Investigação e psicanálise. Campinas: Papirus, 1993. p. 49-89.

MEZAN, R. Interfaces da psicanálise. São Paulo: Companhia das Letras, 2002.

MIELKE, P. Concepção docente sobre o ensino da psicanálise nos cursos de psicologia: um estudo de caso. 2013. Dissertação (Mestrado em Ciências Humanas) Universidade do Oeste Paulista, Presidente Prudente, 2013.

MION, C. C. Algumas reflexões sobre a prática clínica e a formação analítica. Jornal de Psicanálise, v. 47, n. 86, p. 103-111, 2014. Disponível em: http://pepsic.bvsalud.org/scielo.php?script=sci_arttext\&pid=S010358352014000100011\&lng=pt\&nrm=iso. Acesso em: 08 jan. 2020.

MONTEIRO, E. A. Sobre uma especificidade do ensino da psicanálise na universidade: a formação de educadores. In: COLÓQUIO DO LEPSI IP/FE-USP, 3, 2001, São Paulo.

Proceedings online [...]. São Paulo: USP,2001. Disponível em: http://www.proceedings.scielo.br/scielo.php?script=sci_arttext\&pid=MSC000000003 2001000300034\&lng=en\&nrm=abn. Acesso em: 12 set. 2017. 
NUNES, M. R. M. Psicanálise e educação: pensando a relação professor-aluno a partir do conceito de transferência. In: COLÓQUIO DO LEPSI IP/FE- USP, 5, São Paulo, 2004. Anais [...]. São Paulo: USP, 2004.

ROMERA, M. L. C.; ALVARENGA, C. O ensino da psicanálise na universidade: do legado de um impossível à invenção de possibilidades. Jornal de Psicanálise, v. 43, n. 79, p. 187-199, 2010. Disponível em: http://pepsic.bvsalud.org/scielo.php?script=sci_arttext\&pid=S010358352010000200014\&lng=pt\&nrm=iso. Acesso em: 08 jan. 2020.

ROSA, M. D. Psicanálise na universidade: considerações sobre o ensino de psicanálise nos cursos de psicologia. Psicologia USP, v. 12, n. 2, p. 189-199, 2001. Disponível em: http://www.scielo.br/scielo.php?script=sci_arttext\&pid=S010365642001000200016\&lng=en\&nrm=iso. Acesso em: 08 jan. 2020.

SANTOS, T.C. Do saber suposto ao saber exposto: a experiência analítica e a investigação em psicanálise. In: BEIVIDAS, W. (org.). A psicanálise e a pesquisa em universidade. Rio de Janeiro: Contracapa, 2002. p. 71-83.

SANTOS FILHO, F.C. Psicanálise, sua transmissão na universidade e o futuro: reflexões sobre uma experiência. Jornal de Psicanálise, v. 46, n. 85, p. 61-75, 2013. Disponível em: http://pepsic.bvsalud.org/scielo.php?script=sci_arttext\&pid=S0103$58352013000200007 \&$ Ing=pt\&nrm=iso. Acesso em: 08 jan. 2020.

SOUZA, O. Aspectos do encaminhamento da questão da cientificidade da psicanálise no movimento psicanalítico. In: PACHECO, R. A.; COELHO JÚNIOR, N.; ROSA, M. D. (org.). Ciência, pesquisa, representação e realidade em psicanálise. São Paulo: Educ/Casa do Psicólogo, 2000. p. 205-233.

TURATO, E. R. Métodos qualitativos e quantitativos na área da saúde: definições, diferenças e seus objetos de pesquisa. Revista de Saúde Pública, v. 39, n. 3, p. 507514, 2005. Disponível em:

http://www.scielo.br/scielo.php?script=sci_arttext\&pid=S0034$89102005000300025 \&$ Ing=pt\&nrm=iso. Acesso em: 08 jan. 2020.

TURATO, E. R. Tratado da metodologia da pesquisa clínico-qualitativa: construção teórico-epistemológica, discussão comparada e aplicação nas áreas da saúde e humanas. 2 ed. Petrópolis: Vozes, 2003.

Enviado em: 29/03/2019

Aprovado em: 29/10/2020 